OPEN ACCESS

Edited by:

El-Sayed M. Abdelwhab, Friedrich Loeffler Institut, Germany

Reviewed by:

Ahmed Sayed Abdel-Moneim Taif University, Saudi Arabia Julie McAuley,

The University of Melbourne, Australia

*Correspondence:

Zejun L

lizejun@shvriac.cn

Hongjun Chen

vetchj@shvriac.cn

Specialty section:

This article was submitted to

Virology,

a section of the journal

Frontiers in Microbiology

Received: 03 September 2018

Accepted: 18 February 2019

Published: 11 March 2019

Citation:

Sun $H$, Wang K, Yao W, Liu Q,

Yang J, Teng Q, Li X, Li Z and Chen H (2019) H9N2 Viruses Isolated From

Mammals Replicated in Mice

at Higher Levels Than Avian-Origin

Viruses. Front. Microbiol. 10:416.

doi: 10.3389/fmicb.2019.00416

\section{H9N2 Viruses Isolated From Mammals Replicated in Mice at Higher Levels Than Avian-Origin Viruses}

\author{
Haiwei Sun ${ }^{1}$, Kai Wang ${ }^{1}$, Wei Yao ${ }^{1}$, Qinfang Liu',2, Jianmei Yang ${ }^{1,2}$, Qiaoyang Teng ${ }^{1,2}$, \\ Xuesong $\mathrm{Li}^{1,2}$, Zejun $\mathrm{Li}^{1,2 *}$ and Hongjun Chen ${ }^{1,2 *}$ \\ ${ }^{1}$ Shanghai Veterinary Research Institute, Chinese Academy of Agricultural Sciences, Shanghai, China, ${ }^{2}$ Animal Influenza \\ Virus Ecology and Pathogenesis Innovation Team, The Agricultural Science and Technology Innovation Program, Shanghai, \\ China
}

H9N2 subtype influenza A virus (IAV) has more than 20 genotypes that are able to cross species barriers and expand from birds to mammals and humans. To better understand the impact of different H9N2 genotypes and their characteristics, five H9N2 viruses from different hosts including chickens, geese, pigs, mink, and humans representing the B69 88(Gs/14, CK/15, and Mi/14), B35 (Sw/08) and G9 genotypes (Hu/04) were infected in chicken and mice. In mice, mammal-origin viruses replicated at higher levels in the lungs compared to avian viruses. The goose-virus replicated at the lowest levels indicating poor adaptation. Increased pro-inflammatory cytokines were positively correlated with viral loads in the lung. In chickens, all viruses were excreted from cloacal and/or oropharyngeal swabs. Interestingly, Mink-origin virus exhibited higher virulence and replication in mice and chickens. Our data indicate that mammal-origin H9N2 viruses are more adapted and virulent in mice than the avian-origin viruses.

Keywords: influenza A virus, H9N2, subtype, genotype, pathogenicity

\section{INTRODUCTION}

H9N2 was considered to be a low pathogenicity avian influenza virus (AIV) because it causes mild clinical disease (Cauthen et al., 2000). Poultry infected with AIV H9N2 are important incubators for novel emerging pandemic AIVs (Liu et al., 2014; Sun and Liu, 2015), which contribute to the reassortment of new human H7N9 or H10N8 influenza viruses (Pu et al., 2015). In mainland China, H9N2 virus was first isolated from chickens in Guangdong Province in 1994 (Zhao et al., 2015), and then from humans 5 years later in Hong Kong (Guo et al., 1999). H9N2 viruses reassort with a variety of other subtypes to form novel influenza virus genotypes. Moreover, H9N2 viruses were reported to have evolutionary human-like receptor identity with a Q226L substitution in the hemagglutinin (HA) glycoprotein and have adapted to bind mammalian host receptors, which led to an increase in human susceptibility (Matrosovich et al., 2001). Thus, the subtype was suggested to be a considerable threat to public health (Lin et al., 2000; Saito et al., 2001; Butt et al., 2005). 
H9N2 influenza viruses have evolved by reassortment and mutation over 25 years of prevalence in poultry. The "fittest" genotype, G57, changed antigenicity, which resulted in viral escape from immunization and caused widespread outbreaks in 2010-2015 and finally became the single predominant genotype in Chinese farmed chickens. Moreover, the genotype G57 of H9N2 subtype AIV contributed its six internal segments to the novel H7N9 viruses by reassortment in 2013. The widespread use of vaccines against $\mathrm{H} 9 \mathrm{~N} 2$ viruses in chickens has exerted continuous immune pressure on the hemagglutinin (HA) glycoprotein with antigenic drift (Pu et al., 2015).

To date, little information has been available on the host response and cytokine production in response to AIV H9N2 infection. In this paper, the pathogenicity of H9N2 viruses was investigated in mice and chickens to determine immunological patterns with different genotypes.

\section{MATERIALS AND METHODS}

\section{Ethics Statement for Animal Usage}

All animal studies were carried out in strict accordance with the recommendations in the guide of Shanghai Veterinary Research Institute, CAAS (ID: SHVRI-PO-2014-0098) and approved by the Animal Association of Science and Technology Commission of Shanghai Municipality, China (Permit Number: 2013-11).

\section{Cell Culture and Reagents}

Human embryonic kidney 293T (HEK 293T) cell line and Madin Darby canine kidney (MDCK) cell line were maintained in Dulbecco's modified Eagle's medium (DMEM; HyClone, United States) containing 5\% fetal bovine serum (FBS; PAN Biotech, Germany) and $1 \%$ penicillin-streptomycin solution (PS; Thermo Fisher Scientific., United States) at $37^{\circ} \mathrm{C}$ with $5 \% \mathrm{CO}_{2}$.

\section{Viruses}

Five H9N2 influenza A virus strains were isolated from different hosts. Strain Sw/08 was isolated from a Jiangsu swine farm in 2008 with mild respiratory disease and named A/swine/Jiangsu/ Sw/08/08 (abbr. Sw/08). Strain Ck/15 was isolated from an Anhui chicken farm in 2015 and named A/chicken/Anhui/120/2015 (abbr. Ck/15). Strain Gs/14 was isolated from a Jiangsu goose farm in 2014 and named A/goose/Jiangsu/4539/2014 (abbr. $\mathrm{Gs} / 14$ ). Strain $\mathrm{Hu} / 04$ was isolated from humans in 2004 and named A/Guangdong/Hu/04/2004 abbr. Hu/04). Strain $\mathrm{Mi} / 14$ was isolated from mink in 2014 and named $\mathrm{A} / \mathrm{mink}$ / China/01/2014 (abbr. Mi/14). H9N2 viruses were grown by inoculation in 9 days-old specific pathogen-free chicken eggs (Merialvital, Co., Beijing). The allantoic fluids were collected $48 \mathrm{~h}$ later and stored at $-80^{\circ} \mathrm{C}$ until use (Jin et al., 2018). The viral titers were determined and calculated according to the Reed-Muench method (Reed and Muench, 1938; Brown, 1964) for a $50 \%$ tissue culture infectious dose $\left(\mathrm{TCID}_{50}\right)$ on MDCK cells with MEM (Hyclone Laboratories, San Angelo, TX, United States) with $1 \mu \mathrm{g} / \mathrm{ml}$ trypsin treated with
L-(tosylamido-2-phenyl) ethyl-chloromethyl ketone (TPCK) (Chen et al., 2014a).

\section{Sequencing and Phylogenic Analysis of the H9N2 Viruses}

Total RNA was extracted by using the RNeasy kit (Qiagen, Inc., Gaithersburg, MD, United States) following the manufacturer's instructions. Reverse transcription was carried out using the Uni12 primer (5'-AGCAAAAGCAAGG-3') and avian myeloblastosis virus (AMV) reverse transcriptase (Takara) following the manufacturer's instructions and the cDNA products were stored at $-80^{\circ} \mathrm{C}$ until use. The eight segments of influenza A virus were amplified by PCR using universal primers (Wang et al., 2017) and Phusion high-fidelity DNA polymerase (Vazyme, Inc., Nanjing, China). The PCR products were cloned into the pHW2000 vector using an in vitro recombination approach (Wang et al., 2017). The cloned plasmids were confirmed by sequencing with the Sanger method (Genewiz, Inc., Suzhou, China) with primers: 5'-CGCAAATGGGCGGTAGGCGTG-3' (CMV-Forward) and 5'-TAGAAGGCACAGTCGAGG-3' (BGHReverse). The eight segments of H9N2 virus were analyzed and aligned by using MEGA6 software (Tamura et al., 2013).

\section{Pathogenicity of H9N2 Viruses in Chickens}

To identify the pathogenicity of H9N2 viruses in chickens, Eight SPF chickens (4-week-old) per group were intranasally inoculated at an equal dose of $1 \times 10^{6} \mathrm{TCID}_{50}$ per $100 \mu \mathrm{l}$ diluted in PBS buffer. Negative control chickens received $100 \mu \mathrm{l}$ PBS. After infection, SPF chickens were monitored daily for 14 days. Oropharyngeal and cloacal swabs were collected at $1,3,5$ days post-inoculation (dpi) and then stored at $-80^{\circ} \mathrm{C}$ in $1 \mathrm{ml}$ PBS buffer containing $100 \mathrm{U} / \mathrm{ml}$ penicillin and $0.05 \mathrm{mg} / \mathrm{ml}$ streptomycin. Three chickens from each challenge group were randomly euthanized at $3 \mathrm{dpi}$ and the trachea samples were collected and fixed in 10\% formalin and subsequently embedded in paraffin for hematoxylin and eosin (H\&E) staining. Meanwhile, the lung samples were collected and homogenized using a Tissue Lyser at 70 times 1/s for 2 min (Chen et al., 2014a), and centrifuged at $13,200 \times g$ for $10 \mathrm{~min}, 100 \mu \mathrm{l}$ aliquots of the supernatants were collected and the titers were determined on MDCK cells. The pathogenic scores were measured based on the distribution of tracheal lesions (Gibson-Corley et al., 2013). The remaining chickens were monitored daily for clinical signs then euthanized at $14 \mathrm{dpi}$.

The infected lung tissues were homogenized and total RNA was extracted (Sun et al., 2017). The cDNA synthesis was driven by AMV transcriptase (Takara) with Oligo $(\mathrm{dT})_{18}$ in $20 \mathrm{\mu l}$ volumes at $30^{\circ} \mathrm{C}$ for $10 \mathrm{~min}, 42^{\circ} \mathrm{C}$ for $2 \mathrm{~h}$, and then $70^{\circ} \mathrm{C}$ for $15 \mathrm{~min}$. The primers of qRT-PCR were designed using PrimerQuest Tool. The sequences of the primers were as follows: qck $\beta$-actin-F: TCCCTGGAGAAGAGCTATGAA; qck $\beta$-actin-R: CAGGACTCCATACCCAAGA AAG. qckIL-1 $\beta$-F: CTCACAGT CCTTCGACATCTTC; qckIL-1 $\beta$-R: TGTTGAGCC TCACTTTC TGG. qckIL-6-F: TCTGTTCGCCTTTCAGACCTA; qckIL-6-R: GACCACCTCATCGGGATTTAT. qckTNF- $\alpha-F$ : CCGCCCA 


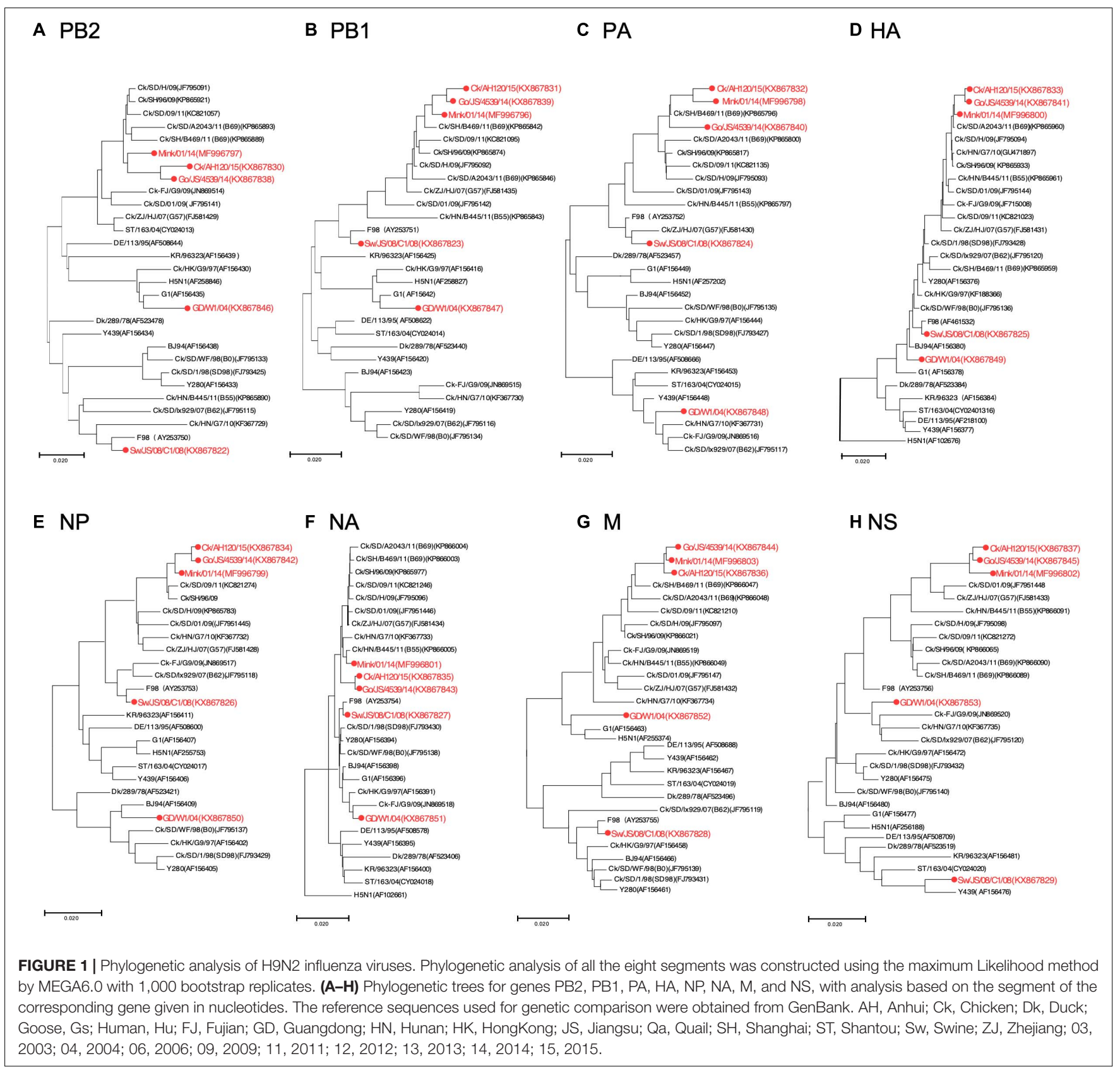

GTTCAGATGAGTT; qckTNF- $\alpha$-R: GCAACAACCAGCTA TGCACC. qckMCP- $1 \alpha-\mathrm{F}$ : CCCACAACTGCC ATAGATGAA; qckMCP-1 $\alpha-\mathrm{R}$ : GCTTTCCCGAGGGCAATAA; qckMIP-1-F: GGGCTCTGTTTCTCTCTCTTC; qckMIP-1-R: CATTTGCTG CTGGTGATGTAG. The reactions were conducted by qRT-PCR analysis with AceQ ${ }^{\circledast} \mathrm{qPCR}^{\mathrm{SPBR}}{ }^{\circledast}$ Green Master Mix (Vazyme) according to the following cycle protocol: $95^{\circ} \mathrm{C}$ for $5 \mathrm{~min}$, 40 cycles at $95^{\circ} \mathrm{C}$ for $10 \mathrm{~s}$, and $60^{\circ} \mathrm{C}$ for $30 \mathrm{~s}$ or followed by the melt curve stage $\left(95^{\circ} \mathrm{C}\right.$ for $15 \mathrm{~s}, 60^{\circ} \mathrm{C}$ for $1 \mathrm{~min}$, and $95^{\circ} \mathrm{C}$ for $15 \mathrm{~s})$. The reaction results were represented by threshold cycle (Ct) values. The fold change was calculated using the $2^{-\Delta \Delta \mathrm{Ct}}$ method (Huang et al., 2017). Mean Ct values were determined based on triplicates.

\section{Flow Cytometry}

Chicken peripheral blood mononuclear leukocytes (PBML) were isolated from chicken wing veins using a Ficoll-paque (Amersham Pharmacia Biotech, Piscataway, NJ, United States) with a density gradient of $50 \times \mathrm{g}$ at $4^{\circ} \mathrm{C}$ for $30 \mathrm{~min}$, and washed three times with PBS containing $1 \%$ FBS. PBML cells were incubated with FITC-labeled anti-chicken CD3 antibody (1:50) (Southern Biotech, Cambridge, United Kingdom), PE-labeledanti chicken CD4 antibody (1:50) (Southern Biotech), and APClabeled-anti chicken CD8 antibody (1:50) (Southern Biotech) for $20 \mathrm{~min}$ at $4^{\circ} \mathrm{C}$, washed with PBA (PBS, $0.5 \% \mathrm{BSA}$, and $0.0001 \%$ sodium azide) and then incubated with a goat anti-chicken IgG (Southern Biotech) for $20 \mathrm{~min}$ at $4^{\circ} \mathrm{C}$. The stained cells were 


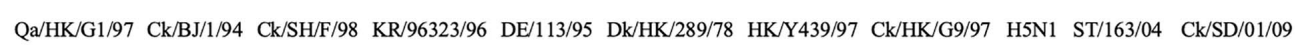

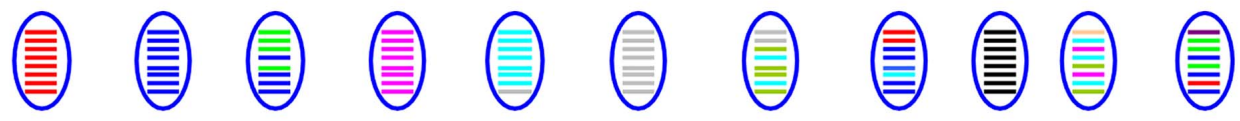

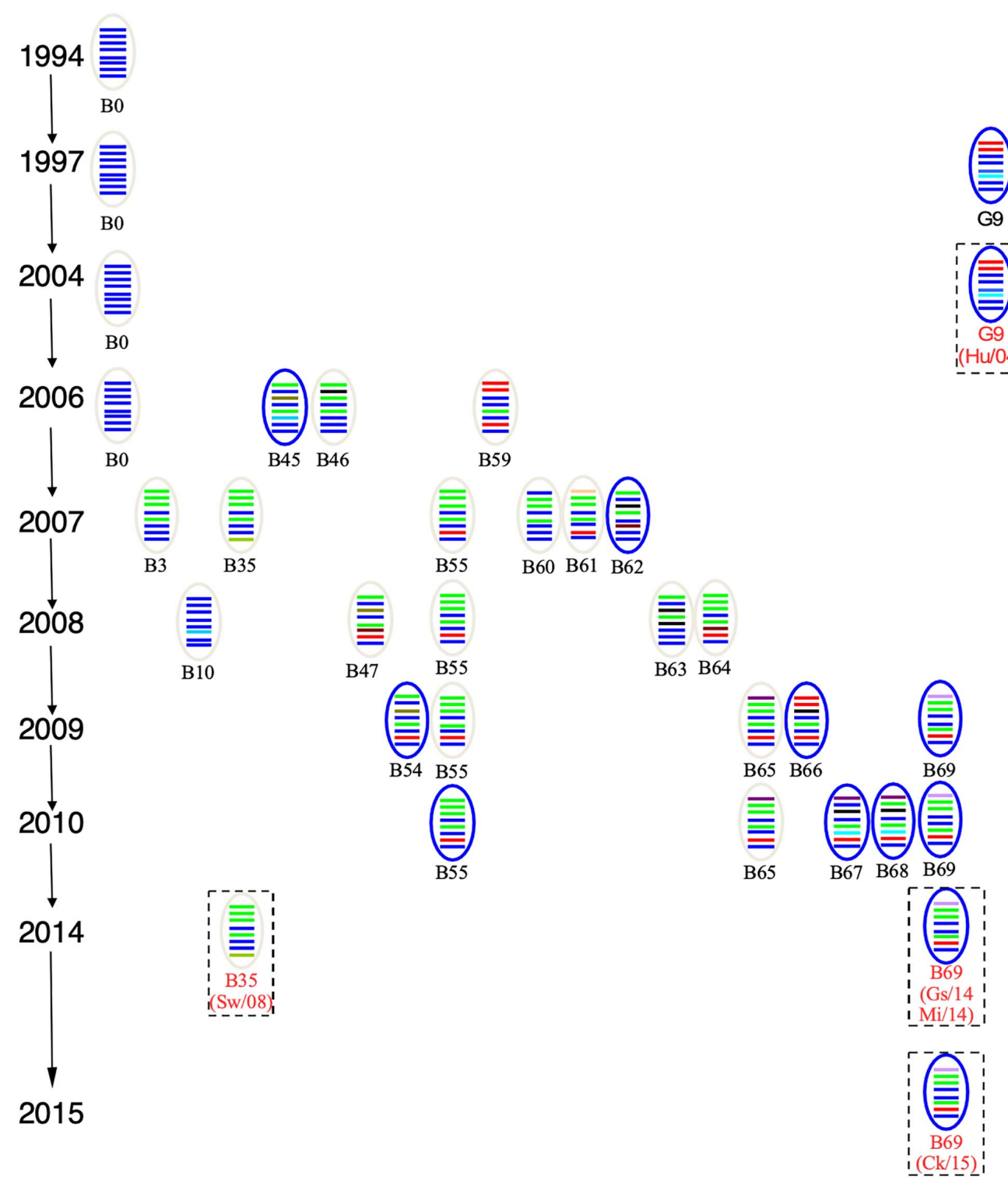

FIGURE 2 | Genotypes of H9N2 influenza viruses. In the ovals, horizontal bars from top to bottom stand for PB2, PB1, PA, HA, NP, NA, M, and NS. A/Quail/Hong Kong/G1/1997 (Qa/HK/G1/97) was isolated from quail in 1997 in Hong Kong, the NCBI taxon ID was 97352 and representing genotype G1. A/Chicken/Beijing/1/1994 (CK/BJ/94) was isolate from chicken in 1994 in Beijing, the NCBI taxon ID was 1342391 and representing genotype BJ94. A/Chicken/ Hong Kong/G9/1997 (CK/HK/G9/97) was isolate from chicken in 1997 in Hong Kong, the NCBI taxon ID was 1342394 and representing genotype G9. A/Chicken/Korea/38349-p96323/1996 (CK/KR/96323/96) was isolate from chicken in 1996 in Korea, the NCBI taxon ID was 97358 and representing genotype C0. A/Chicken/Shandong/01/2009 (CK/SD/01/09) was isolate from chicken in 2009 in Shandong, the NCBI taxon ID was 1005638 and representing genotype B65. A/Chicken/Shanghai/F/1998 (CK/SH/F/98) was isolate from chicken in 1998 in Shanghai, the NCBI taxon ID was 183741 and representing genotype F/98. A/Chicken/Zhejiang/B2013/2012 (CK/ZJ/B2013/12) was isolate from chicken in 2013 in Zhejiang, the NCBI taxon ID was 1621010 and representing genotype B69. A/Duck/Hong Kong/289/1978 (DK/HK/289/78) was isolate from duck in 1978 in Hong Kong, the NCBI taxon ID was 210667 and representing genotype E0. A/Duck/ Hong Kong/Y439/1997 (DK/HK/Y439/97) was isolate from duck in 1997 in Hong Kong, the NCBI taxon ID was 1342412 and representing genotype Y439. A/Duck/Germany/113/1995 (DK/GE/113/95) was isolate from duck in 1978 in Germany, the NCBI taxon ID was 1175984 and representing genotype D1. A/Duck/ Fujian/ C2246 (DK/FJ/C2246/09) was isolate from duck in 2009 in Fujian, the NCBI taxon ID was 1521103 and representing genotype B67. A/Duck/Shantou/163/2004 (Dk/ST/163/04) was isolate from duck in 2004 in Shantou, the NCBI taxon ID was 456814 and representing genotype ST/163. A Chicken/Hong Kong/715.5/2001 (H5N1) (H5N1/01) was isolate from chicken in 2001 in Hong Kong, the NCBI taxon ID was 196434 (Bi et al., 2011 ; Dong et al., 2011; Teng et al., 2016). 
TABLE 1 | Amino acid mutations in the five characterized H9N2 viruses.

\begin{tabular}{|c|c|c|c|c|c|c|}
\hline \multirow[t]{2}{*}{ Segment } & \multirow[t]{2}{*}{ aa position } & \multicolumn{5}{|c|}{ Amino acid substitution } \\
\hline & & Sw/08 & $\mathrm{Hu} / 04$ & Gs/14 & Ck/15 & $\mathrm{Mi} / 14$ \\
\hline \multirow[t]{9}{*}{ PB2 } & 87 & $\mathrm{D}$ & $D$ & $\mathrm{~N}$ & $\mathrm{D}$ & $\mathrm{D}$ \\
\hline & 271 & $\mathrm{~T}$ & S & $\mathrm{T}$ & $\mathrm{T}$ & $\mathrm{T}$ \\
\hline & 340 & $\mathrm{~K}$ & $\mathrm{R}$ & $\mathrm{R}$ & $\mathrm{R}$ & $K$ \\
\hline & 396 & $E$ & $E$ & $E$ & $E$ & K \\
\hline & 588 & $A$ & $A$ & $A$ & $A$ & V \\
\hline & 598 & $\mathrm{~T}$ & $\mathrm{~T}$ & V & V & V \\
\hline & 627 & $E$ & $E$ & $E$ & $E$ & $E$ \\
\hline & 676 & $\mathrm{~T}$ & $\mathrm{~T}$ & M & M & M \\
\hline & 701 & $N$ & $D$ & $\mathrm{D}$ & $\mathrm{D}$ & $\mathrm{N}$ \\
\hline \multirow[t]{4}{*}{ PB1 } & 197 & K & K & $\mathrm{R}$ & $\mathrm{R}$ & K \\
\hline & 322 & 1 & I & I & 1 & $M$ \\
\hline & 434 & $\mathrm{~T}$ & $\mathrm{~T}$ & $\mathrm{~N}$ & $\mathrm{~N}$ & $\mathrm{~T}$ \\
\hline & 525 & 1 & I & 1 & 1 & V \\
\hline \multirow[t]{2}{*}{ PB1-F2 } & 51 & M & $\mathrm{T}$ & $\mathrm{T}$ & $\mathrm{T}$ & $\mathrm{T}$ \\
\hline & 79 & $\mathrm{R}$ & $L$ & $\mathrm{R}$ & $\mathrm{R}$ & $R$ \\
\hline \multirow[t]{6}{*}{ PA } & 70 & A & A & V & A & A \\
\hline & 100 & V & V & V & $A$ & $A$ \\
\hline & 356 & K & K & $\mathrm{R}$ & $\mathrm{R}$ & $\mathrm{R}$ \\
\hline & 394 & $D$ & $D$ & $\mathrm{D}$ & $N$ & $\mathrm{~N}$ \\
\hline & 594 & S & S & $\mathrm{R}$ & $S$ & S \\
\hline & 614 & $N$ & $N$ & $N$ & $N$ & S \\
\hline \multirow[t]{3}{*}{$\mathrm{HA}$} & 191 & $\mathrm{~N}$ & $\mathrm{~N}$ & $\mathrm{~N}$ & $\mathrm{~N}$ & $\mathrm{H}$ \\
\hline & 226 & $\mathrm{G}$ & $G$ & $\mathrm{G}$ & $\mathrm{G}$ & $\mathrm{G}$ \\
\hline & 228 & $\mathrm{R}$ & $\mathrm{R}$ & $\mathrm{R}$ & $\mathrm{R}$ & $R$ \\
\hline \multirow[t]{3}{*}{ NP } & 352 & V & V & $M$ & $\mathrm{M}$ & $M$ \\
\hline & 377 & S & S & $\mathrm{N}$ & $\mathrm{N}$ & $\mathrm{N}$ \\
\hline & 406 & 1 & I & V & V & V \\
\hline \multirow[t]{6}{*}{ NA } & 80 & K & $N$ & $N$ & $\mathrm{~N}$ & $N$ \\
\hline & 125 & $\mathrm{G}$ & $\mathrm{G}$ & $\mathrm{S}$ & $S$ & $S$ \\
\hline & 184 & $\mathrm{H}$ & $\mathrm{H}$ & Y & Y & Y \\
\hline & 199 & $K$ & $K$ & $\mathrm{~T}$ & $\mathrm{~T}$ & $\mathrm{~T}$ \\
\hline & 248 & $\mathrm{G}$ & $\mathrm{G}$ & $\mathrm{G}$ & $\mathrm{G}$ & $x$ \\
\hline & 356 & $S$ & $N$ & $\mathrm{D}$ & $\mathrm{D}$ & $\mathrm{D}$ \\
\hline \multirow[t]{8}{*}{ M1 } & 37 & $\mathrm{~T}$ & $\mathrm{~T}$ & $A$ & A & A \\
\hline & 95 & $\mathrm{R}$ & $\mathrm{R}$ & $\mathrm{K}$ & $\mathrm{K}$ & $\mathrm{K}$ \\
\hline & 140 & $\mathrm{~T}$ & $\mathrm{~T}$ & A & $A$ & $A$ \\
\hline & 142 & V & V & $\mathrm{G}$ & $\mathrm{G}$ & $\mathrm{G}$ \\
\hline & 219 & 1 & 1 & V & V & V \\
\hline & 224 & S & S & $N$ & $N$ & $\mathrm{~N}$ \\
\hline & 242 & K & K & $\mathrm{N}$ & $N$ & $\mathrm{~N}$ \\
\hline & 247 & $\mathrm{M}$ & $\mathrm{M}$ & $L$ & $L$ & $L$ \\
\hline \multirow[t]{5}{*}{ M2 } & 16 & $\mathrm{G}$ & $E$ & $E$ & $E$ & $E$ \\
\hline & 21 & $D$ & $\mathrm{G}$ & $G$ & $\mathrm{G}$ & $\mathrm{G}$ \\
\hline & 31 & S & S & $\mathrm{N}$ & $\mathrm{N}$ & $\mathrm{N}$ \\
\hline & 68 & V & V & $M$ & $\mathrm{M}$ & $M$ \\
\hline & 82 & $S$ & $\mathrm{~N}$ & $N$ & $\mathrm{~N}$ & $N$ \\
\hline \multirow[t]{7}{*}{ NS1 } & 47 & $\mathrm{G}$ & $\mathrm{G}$ & S & S & $S$ \\
\hline & 80 & $\mathrm{~T}$ & $\mathrm{~T}$ & $S$ & $S$ & $S$ \\
\hline & 103 & S & $\mathrm{L}$ & $\mathrm{L}$ & $\mathrm{L}$ & $\mathrm{L}$ \\
\hline & 106 & $\mathrm{~L}$ & 1 & 1 & $\mathrm{~L}$ & V \\
\hline & 163 & $L$ & $\mathrm{~L}$ & $L$ & $L$ & V \\
\hline & 212 & $P$ & $\mathrm{P}$ & $S$ & $S$ & $s$ \\
\hline & 216 & $P$ & $\mathrm{P}$ & $\mathrm{T}$ & $\mathrm{T}$ & $\mathrm{T}$ \\
\hline \multirow[t]{2}{*}{ NEP } & 14 & $M$ & $M$ & $\mathrm{~T}$ & $\mathrm{~T}$ & $\mathrm{~T}$ \\
\hline & 21 & $\mathrm{G}$ & $\mathrm{G}$ & $\mathrm{R}$ & $\mathrm{R}$ & $\mathrm{R}$ \\
\hline
\end{tabular}

washed with PBS buffer and fixed with $2 \%$ paraformaldehyde (Merck, Inc., Germany) for $10 \mathrm{~min}$ at room temperature. The cells were washed once in PBA buffer. At least 10,000 events were acquired using a FACS Calibur flow cytometer (BD Biosciences, San Jose, CA, United States) and the data were analyzed using FlowJO (Three Star, Inc., Ashland, OR, United States).

\section{Pathogenicity of H9N2 Viruses in Mice}

To determine the virulence of the $\mathrm{H} 9 \mathrm{~N} 2$ viruses in vivo, eight 5-week-old female BALB/c mice (Vital-River, Co., Beijing) were infected intranasally. BALB/c mice were anesthetized with dry ice prior to intranasal inoculation (Jones et al., 1999; Kohler et al., 1999), each received $1 \times 10^{6} \mathrm{TCID}_{50}$ per $50 \mu \mathrm{l}$ intranasally (13 mice/group), with $50 \mu \mathrm{l}$ PBS given to negative control mice. To determine virus titers from the lung, three mice per group were sacrificed at 3 dpi (Chen et al., 2014a). The lung samples were collected and homogenized using a Tissue Lyser at 70 times $1 / \mathrm{s}$ for $2 \mathrm{~min}$ (Chen et al., 2014a), and centrifuged at 13, $200 \times g$ for $10 \mathrm{~min}, 100 \mu \mathrm{l}$ aliquots of the supernatants were collected. The body weights of animals were monitored daily until 14 days after inoculation, and animals with more than $25 \%$ body weight loss were euthanized. The viral titers were titrated on MDCK cells. The levels of IL- $1 \beta$, IL- 6 , MIP- $1 \alpha$, MCP- 1 , and TNF- $\alpha$ in the $100 \mu \mathrm{l}$ aliquots of the homogenized lung samples were measured using sandwich enzyme-linked immunosorbent assay (sELISA) kits (eBioscience, Inc., San Diego, CA, United States) according to the manufacturer's recommendations.

\section{Statistical Analysis}

Statistical analyses were performed using Prism 6 software (GraphPad, La Jolla, CA, United States). Pairwise comparisons between groups means were carried out with a two-stage stepup procedure by Benjamini test, whereas multiple comparisons were carried out by an analysis of variance (one-way ANOVA method). The differences were considered significant at $p$-values of $<0.05$ or $<0.01$.

\section{RESULTS}

\section{Phylogenetic Analysis of H9N2 Subtype IAV Genotypes}

To further characterize the different genotypes of H9N2 subtype influenza A viruses, eight segments of each selected virus were amplified, sub-cloned, and sequenced. The sequences were deposited into GenBank with accessions of the isolate KK (KX867822-KX867829), the isolate Ck/15 (KX867830KX867837), the isolate Gs/14 (KX867838-KX867845), and the isolate $\mathrm{Hu} / 04$ (KX867846-KX867853). The characterization of Mi/14 virus (MF996796-MF996803) was confirmed in a recent report (Xue et al., 2018).

To track the H9N2 viruses, the genetic origin of the subtype was characterized based on phylogenetic analysis of eight segments (Figure 1), which was constructed using the maximum Likelihood method in MEGA6.0 (Tamura et al., 2013) with 1, 000 bootstrap replicates. The reference sequences used for 
A

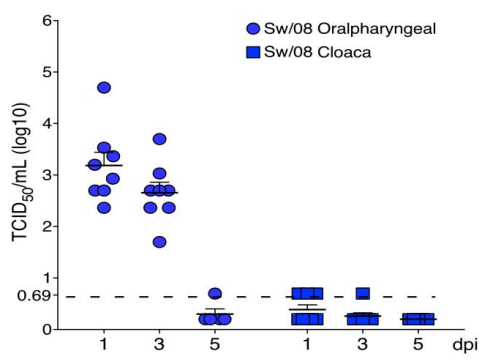

D

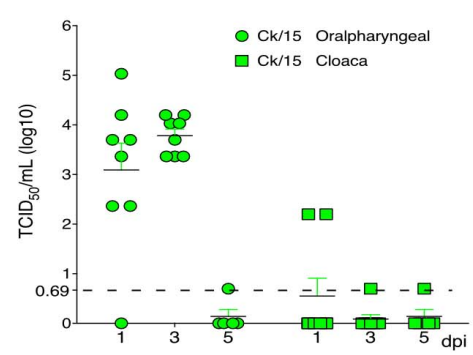

B

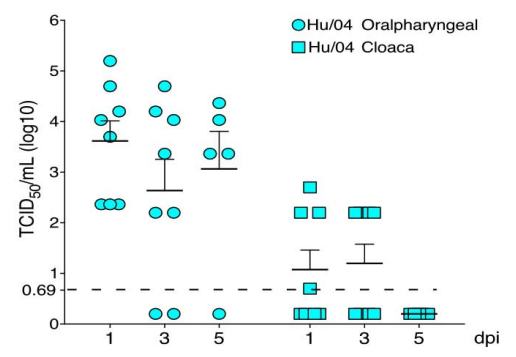

E

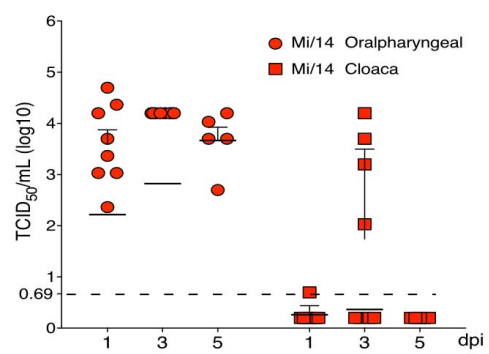

C

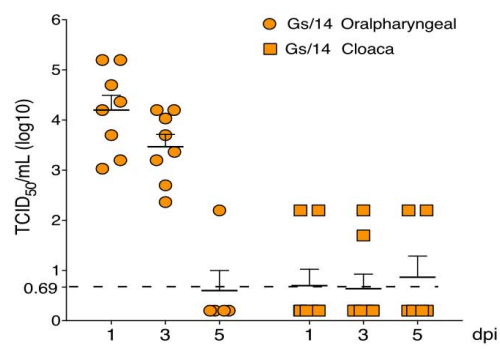

$\mathbf{F}$

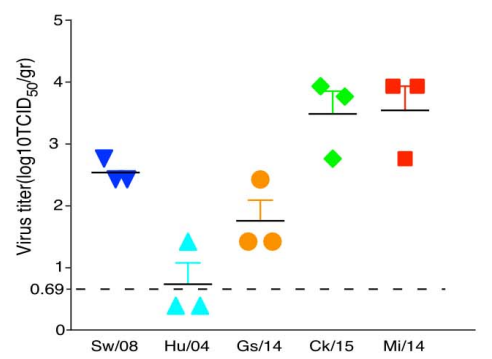

FIGURE 3 | Replication of H9N2 viruses in chickens. Oropharyngeal and cloaca samples from the strains Sw/08 (A), Hu/04 (B), Gs/14 (C) and CK/15 (D) and Mi/14 (E) viruses were tittered by $T_{C I} D_{50}$. Virus load in the lung samples when infection at 3 dpi (F). gr, grams.

genetic comparison were obtained from GenBank. Based on the phylogenetic analysis, three viruses (Gs/14, Ck/15, and $\mathrm{Mi} / 14$ ) belonged to genotype $\mathrm{B} 69$, which is a predominant genotype circulating in China and showed more efficient replication in chickens, isolate Sw/08 belonged to genotype B35 and isolate $\mathrm{Hu} / 04$ fell into genotype G9 (Figure 2) (Dong et al., 2011; Pu et al., 2015; Teng et al., 2016).

Amino acid mutation analysis showed that all viruses had $226 \mathrm{G}$ and $228 \mathrm{R}$ in the HA protein at the receptor binding region, and no deletion in the NA stalk regions was observed in these five H9N2 viruses. However, Gs/14, Ck/15, and Mi/14 shared similar amino acid sequences as compared to Sw/08 and Hu/04 (Table 1). In detail, PB2 (598V, 676M), PA (356R), NP (377N, 406V), NA (80N, 125S, 184Y, 199T, 356D), M1 (37A, 95K, 140A, $142 \mathrm{G}, 224 \mathrm{~N}, 242 \mathrm{~N}, 247 \mathrm{~L}), \mathrm{M} 2(16 \mathrm{E}, 21 \mathrm{G}, 31 \mathrm{~N}, 68 \mathrm{M}, 82 \mathrm{~N}), \mathrm{NS} 1$ (47S, 80S, 103L), and NEP (14T, 21R, 49A) were shown in Table 1. In addition, mammalian adaptation associated mutations were observed in the PB2 gene of $\mathrm{Mi} / 14$ (A588V and D701N) and Sw/08 (D701N) (Sediri et al., 2015; Xiao et al., 2016) viruses. $\mathrm{R} 340 \mathrm{~K}$ was observed in the $\mathrm{PB} 2$ of $\mathrm{Mi} / 14$ and Sw/08 viruses, $522 \mathrm{~V}$ was observed in PB1 of Mi/14 virus (Neumann et al., 2014), which is a potential virulence-related site. PA K356R which increases replication and pathogenicity, was observed in $\mathrm{Gs} / 14, \mathrm{Ck} / 15$, and Mi/14 (Xu et al., 2016).

\section{Pathogenicity of H9N2 Viruses in Chickens}

All five H9N2 viruses replicated well in the oropharyngeal samples at 1 and $3 \mathrm{dpi}$; however, very low virus levels were detected from the oropharyngeal samples of Sw/08, Gs/14, and $\mathrm{Ck} / 15$ viruses at $5 \mathrm{dpi}$. The $\mathrm{Hu} / 04, \mathrm{Gs} / 14$, and $\mathrm{Mi} / 14$ viruses were excreted through the feces (Figures 3A-E). Meanwhile, the viral titers of lung samples at $3 \mathrm{dpi}$ were also homogenized and titrated on MDCK cells, all five $\mathrm{H} 9 \mathrm{~N} 2$ viruses except $\mathrm{Hu} / 04$ replicated well in lungs. Compare to Sw/08 and Gs/14, Ck/15, and Mi/14 show a higher replication ability in chicken lungs (Figure 3F).

To determine the pro-inflammatory response of the five viruses, the 3 dpi lung samples were homogenized to quantify the mRNA levels of IL- $1 \beta$, IL- 6 , TNF- $\alpha$, MIP- 1 , and MCP- $1 \alpha$ (Figure 4A). In detail, the IL-1 $\beta$ mRNA level of $\mathrm{Ck} / 15$ and $\mathrm{Mi} / 14$ increased more than 400-fold compared to the PBS negative control and were also significantly higher than the other three H9N2 strains $(p<0.01)$. The mRNA levels of IL-6 $(p<0.05)$, TNF- $\alpha(p<0.05)$, MIP-1 $(p<0.05)$, and MCP- $1 \alpha(p<0.01)$ also increased at least 10 -fold. All H9N2 viruses caused severe tracheal lesions, with an increase in goblet cells and exudative inflammation, with a mean pathogenic score of 4 (Figure 4B). The mean amounts of $\mathrm{CD}_{8}{ }^{+} \mathrm{T}$ cells were increased to $0.70 \%$ from $0.13 \%$ when chickens were infected with $\mathrm{Sw} / 08$ or Mi/14 (Figure 4C) (Table 2).

\section{Pathogenicity of H9N2 Viruses in Mice}

To evaluate the viral replication in lung samples, three mice from each group were euthanized at 3 dpi (Figure 5). Prior to necropsy, $\mathrm{Mi} / 14$ virus caused clinical signs of ruffled fur and depression. Remarkably, 20\% mortality and significant body weight loss were obeserved at $8 \mathrm{dpi}(p<0.01)$. However, the other viruses caused no major clinical signs (Figure 5A). All the H9N2 viruses replicated in lungs without prior adaptation, except Gs/14. 
A

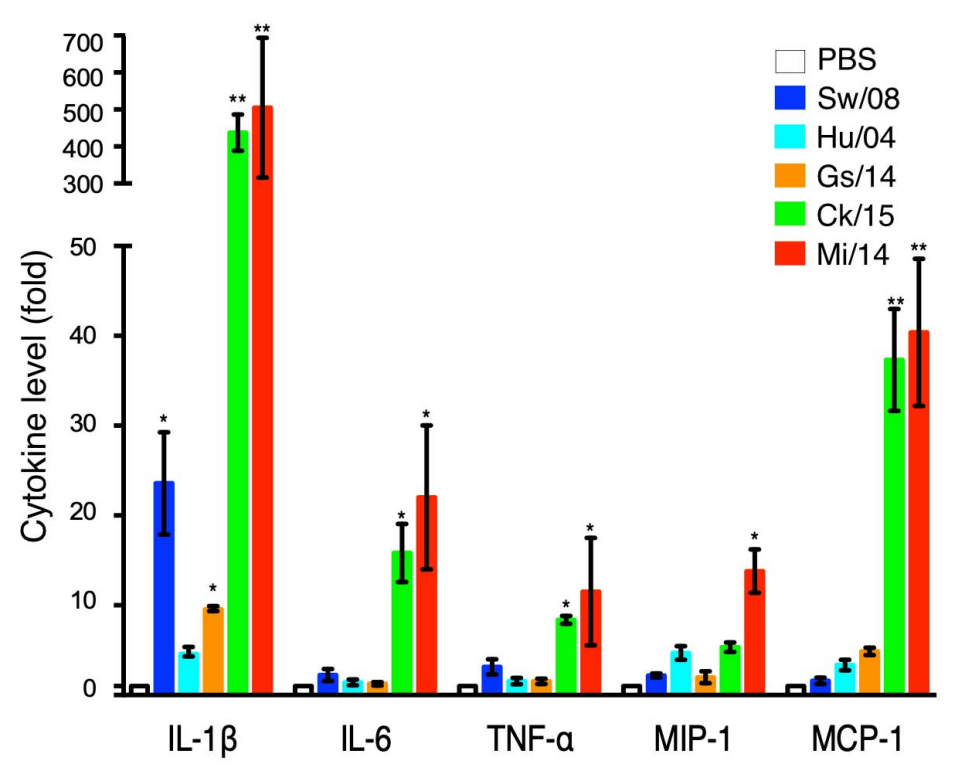

B

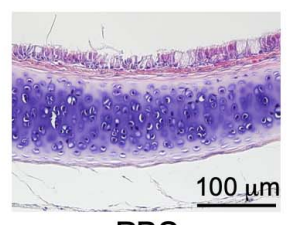

PBS

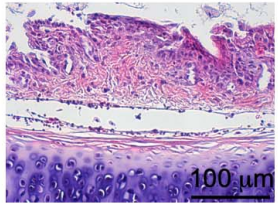

$\mathrm{Hu} / 04$

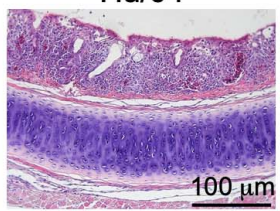

$\mathrm{Ck} / 15$

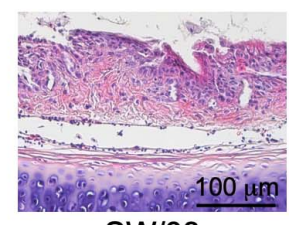

SW/08

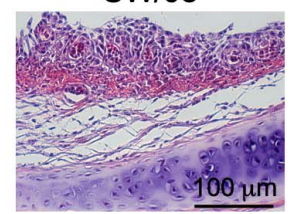

Gs/14

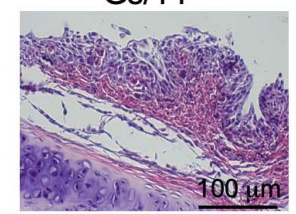

$\mathrm{Mi} / 14$

C
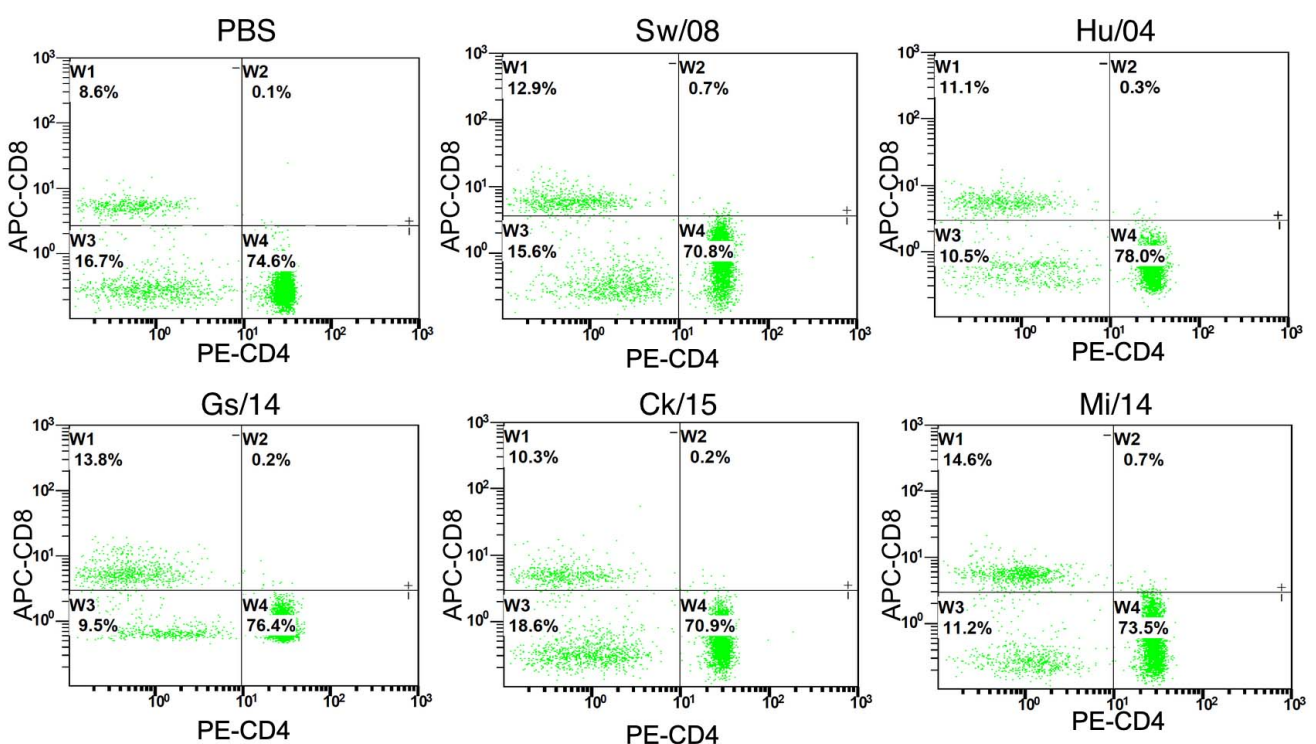

FIGURE 4 | Pro-inflammatory responses and pathogenicity of the H9N2 viruses in chickens. (A) From the homogenized lung samples infected the five H9N2 viruses, the mRNA levels of IL-1 $\beta$, IL-6, TNF- $\alpha$, MIP-1, and MCP-1 $\alpha$ were determined. (B) Histopathological examination with the infected tracheal samples by H\&E staining. (C) FACS analysis to quantify $\mathrm{CD}_{4}{ }^{+}$and $\mathrm{CD}_{8}{ }^{+} \mathrm{T}$ cells. The data represent mean values $\pm \mathrm{SD}$ from three independent experiments in triplicate. ${ }^{*} p<0.05$, $* * p<0.01$.

TABLE 2 | FACS analysis to quantify $\mathrm{CD}_{4}{ }^{+}$and $\mathrm{CD}_{8}+\mathrm{T}$ cells.

\begin{tabular}{|c|c|c|c|c|c|c|}
\hline & PBS & Sw/08 & $\mathrm{Hu} / 04$ & Gs/14 & Ck/15 & $\mathrm{Mi} / 14$ \\
\hline $\mathrm{CD}_{8}+\mathrm{T}$ cells & $16.10 \pm 6.70$ & $14.40 \pm 2.02$ & $11.73 \pm 1.83$ & $11.23 \pm 3.61$ & $13.63 \pm 5.10$ & $19.27 \pm 8.00$ \\
\hline
\end{tabular}

*Represents significant changes compared to the amount of PBS control group $(p<0.05)$.

In detail, at $3 \mathrm{dpi}$, the lung of the mice infected with strain Sw/08 held a high virus load with a mean titer of $1.48 \times 10^{5} \mathrm{TCID}_{50} / \mathrm{gr}$, strain $\mathrm{Hu} / 04$ with a mean titer of $6.01 \times 10^{4} \mathrm{TCID}_{50} / \mathrm{gr}, \mathrm{Ck} / 15$ virus with a mean titer of $1.41 \times 10^{2} \mathrm{TCID}_{50} / \mathrm{gr}, \mathrm{Mi} / 14$ virus with a mean titer of $8.60 \times 10^{4} \mathrm{TCID}_{50} / \mathrm{gr}$. The Sw/08 and Mi/14 viruses showed a higher replication in the lungs of mice, which 
A

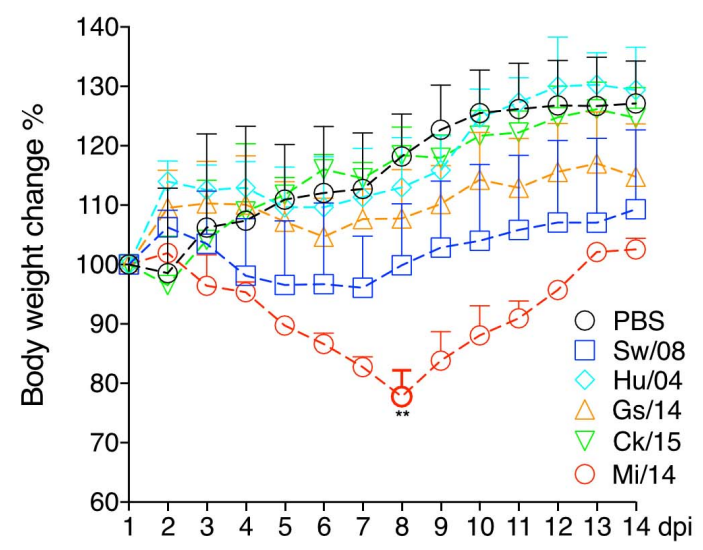

C

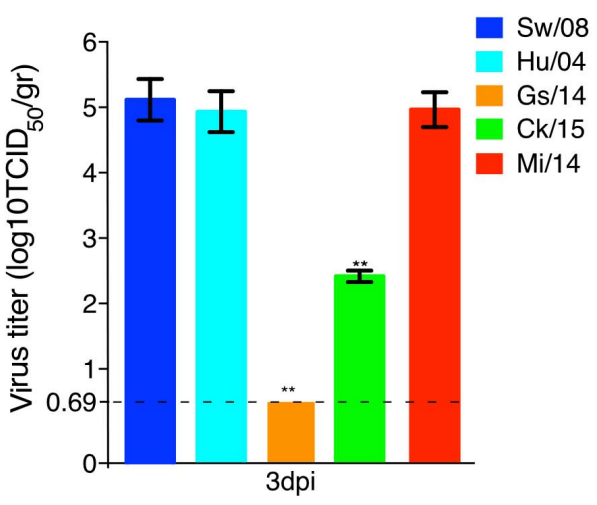

B

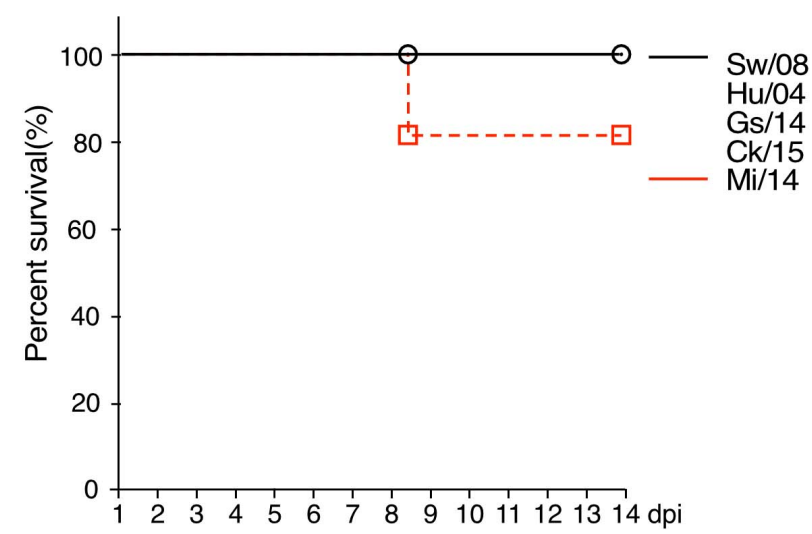

D

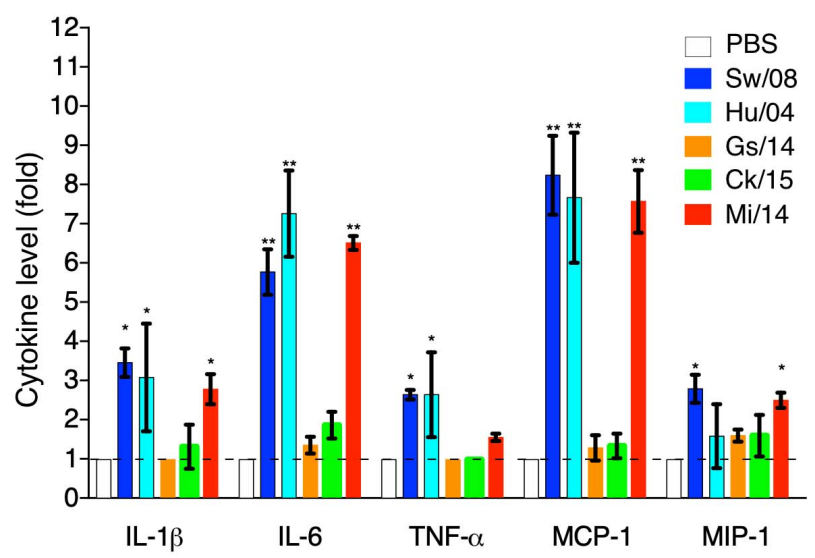

FIGURE 5 | Pathogenicity of H9N2 viruses in mice. The body weight loss (A) and survival (B) were monitored daily until 14 days after inoculation. Virus load in the lung samples when infection at $3 \mathrm{dpi}(\mathbf{C})$. The pro-inflammatory cytokines levels of the mice lung samples at 3 dpi were analyzed by commercial sandwich ELISA kits (D). The data are represented as mean values $\pm \mathrm{SD}$ from three independent experiments in triplicate. ${ }^{*} p<0.05$, ${ }^{* *} p<0.01$. gr, grams.

was 10 to 1,000 -fold higher, as compared with $\mathrm{Hu} / 04$ and $\mathrm{Ck} / 15$ $(p<0.01)$ (Figure 5C), which represented B35 (isolate Sw/08), B69 (isolates Gs/14, Ck/15, and Mi/14) and G9 (isolate Hu/04) genotypes respectively.

Meanwhile, the mice lung samples at 3 dpi were used to check the level of cytokines. The results showed that the mammal-origin Sw/08, Hu/04, and Mi/14 induced stronger proinflammatory responses, as indicated by quantifying IL-1 $\beta$, IL- 6 , TNF- $\alpha$, MCP-1, and MIP- $1 \alpha$ levels using ELISA, as compared with cytokine increases induced by Gs/14 and Ck/15 (Figure 5D).

\section{DISCUSSION}

Different isolates of H9N2 AIV from different genotypes (B69, G1, and B35) were chosen to study the relationship between genotypes and pathotypes. Since 2010, genotype B69 has been predominant in chickens and ducks (Teng et al., 2016) and B69 genotype have been shown to provide internal genes for the emerging $\mathrm{H} 7 \mathrm{~N} 9$ and $\mathrm{H} 10 \mathrm{~N} 8$ viruses in zoonotic infections (Gao et al., 2013; Chen et al., 2014b). High genetic compatibility was indicated in the $\mathrm{B} 69$ genotype, as compared to other IAVs.

H9N2 viruses infect many species (Group, 2013). In mice, the strains Mi/14 (genotype B69) and Sw/08 (genotype B35) showed a higher pathogenicity and a stronger pro-inflammatory response (Figure 5). Obviously, Mi/14 infection showed a remarkable weight loss at $8 \mathrm{dpi}$. Moreover, $20 \%$ of mice died at $8 \mathrm{dpi}$. This suggested that the $\mathrm{Mi} / 14$ virus was more virulent in mice. In chickens, the isolates $\mathrm{Mi} / 14$ (genotype B69) and Ck/15 (genotype B69) showed a higher pathogenicity and a stronger pro-inflammatory response (Figures 3, 4). Interestingly, the higher viral load in lungs showed a higher pro-inflammatory response. It was likely antigenic load to increase the inflammatory response to virus infection. $\mathrm{Hu} / 08$ showed a higher replication in mice but lower in chickens. The human-virus replicated at lower levels in chickens, it was probably that adaptation to humans will decrease the virus replication in chickens. Moreover, Gs/14 
cannot replicate in mice lung but replicate well in chicken. Thus, these data indicate the same virus in different hosts showed a complicated pathotype pattern. It suggested that the pathogenicity of $\mathrm{H} 9 \mathrm{~N} 2$ viruses is strain-dependent.

Our data show that $\mathrm{Sw} / 08, \mathrm{Hu} / 04$, and $\mathrm{Mi} / 14$ replicate well in mice lungs, indicating that the mammal-origin viruses replicated at higher levels than the avian-viruses in mice (Figure 5C). Higher adaptation indicating it is an important step for the virus to transmit from human-to-human. Strikingly, the mammalian adaptation-associated mutation D701N was observed in the PB2 gene of $\mathrm{Mi} / 14$ and Sw/08 viruses. PA sequences of the Sw/08, $\mathrm{Hu} / 04, \mathrm{Ck} / 15$, and $\mathrm{Mi} / 14$ were $70 \mathrm{~A}$ and $594 \mathrm{~S}$, while Gs/14 was $70 \mathrm{~V}$ and $594 \mathrm{~S}$. In addition, R340K was first observed in the PB2 gene of Mi/14 and Sw/08 viruses. These could be a potential virulence determinants that require confirmation.

Extensive studies on how H9N2 viruses affect preinflammatory cytokines expression have also been performed (Geiss et al., 2001, 2002; Kash et al., 2004; Degen et al., 2006; Kobasa et al., 2007). Significant increases in IL-1 $\beta$, IL-6, TNF- $\alpha$, MCP-1, and MIP-1 $\alpha$ in the lungs when H9N2 infected. However, the chicken results of decreased IL- $1 \beta$ induced by $\mathrm{Hu} / 04$ virus compare with Sw/08, Ck/15, and Mi/14. However, the Hu/04 virus in mice yielded the same level of IL-1 $\beta$ production compared to $\mathrm{Mi} / 14$ and Sw/08 viruses, indicating differences in host-specific responses to viral antigen. Taken together, these five cytokines may be key factors for pulmonary pathology. One reason for the differences in levels of IL-1 $\beta$ production is the ability for activation of the inflammasome complex upon recognition of viral antigen, such as PB1-F2 (McAuley

\section{REFERENCES}

Alymova, I. V., McCullers, J. A., Kamal, R. P., Vogel, P., Green, A. M., Gansebom, S., et al. (2018). Virulent PB1-F2 residues: effects on fitness of H1N1 influenza A virus in mice and changes during evolution of human influenza A viruses. Sci. Rep. 8:7474. doi: 10.1038/s41598-018-25707-y

Bi, Y., Lu, L., Li, J., Yin, Y., Zhang, Y., Gao, H., et al. (2011). Novel genetic reassortants in H9N2 influenza A viruses and their diverse pathogenicity to mice. Virol. J. 8:505. doi: 10.1186/1743-422X-8-505

Brown, W. F. (1964). Variance estimation in the reed-muench fifty per cent end-point determination. Am. J. Hyg. 79, 37-46.

Butt, K. M., Smith, G. J., Chen, H., Zhang, L. J., Leung, Y. H., Xu, K. M., et al. (2005). Human infection with an avian H9N2 influenza A virus in Hong Kong in 2003. J. Clin. Microbiol. 43, 5760-5767. doi: 10.1128/JCM.43.11.5760-5767. 2005

Cauthen, A. N., Swayne, D. E., Schultz-Cherry, S., Perdue, M. L., and Suarez, D. L. (2000). Continued circulation in China of highly pathogenic avian influenza viruses encoding the hemagglutinin gene associated with the $1997 \mathrm{H} 5 \mathrm{~N} 1$ outbreak in poultry and humans. J. Virol. 74, 6592-6599. doi: 10.1128/JVI.74. 14.6592-6599.2000

Chen, H., Angel, M., Li, W., Finch, C., Gonzalez, A. S., Sutton, T., et al. (2014a). All-in-one bacmids: an efficient reverse genetics strategy for influenza A virus vaccines. J. Virol. 88, 10013-10025. doi: 10.1128/JVI.01468-14

Chen, H., Yuan, H., Gao, R., Zhang, J., Wang, D., Xiong, Y., et al. (2014b). Clinical and epidemiological characteristics of a fatal case of avian influenza A H10N8 virus infection: a descriptive study. Lancet 383, 714-721. doi: 10.1016/S01406736(14)60111-2

Degen, W. G., Smith, J., Simmelink, B., Glass, E. J., Burt, D. W., and Schijns, V. E. (2006). Molecular immunophenotyping of lungs and spleens in naive and vaccinated chickens early after pulmonary avian influenza A (H9N2) virus infection. Vaccine 24, 6096-6109. doi: 10.1016/j.vaccine.2006.05.027 et al., 2013). Interestingly, the inflammasome activationassociated mutation site $79 \mathrm{R}$ was observed in the PB1-F2 of all five $\mathrm{H} 9 \mathrm{~N} 2$ viruses except $\mathrm{Hu} / 04$ virus (Alymova et al., 2018) (Table 1). Our results indicated that even LPAI H9N2 viruses replicated well in mice and chickens, and could cause significant increases in pro-inflammatory cytokine expression (Figures 4A, 5D). Future reverse genetic assays to engineer point mutations may reveal molecular mechanism of the virulence of H9N2 viruses.

\section{AUTHOR CONTRIBUTIONS}

HC conceived and designed the study. HS, KW, and WY developed the methodology. QL, JY, QT, and XL acquired the data (provided animals, materials, regents, facilities, etc.). HS, KW, and $\mathrm{HC}$ analyzed and interpreted the data. HS and HC wrote, reviewed, and/or revised the manuscript. HC and ZL supervised the study.

\section{FUNDING}

This work was supported by the National Natural Science Foundation of China (Grant No. 31572502), the National Key Research and Development Program of China (Grant Nos. 2017YFD0500702 and 2017YFD0502302), and the Key Project for Agriculture from Shanghai Agriculture Commission (Grant No. 201702080008F00068).

Dong, G., Luo, J., Zhang, H., Wang, C., Duan, M., Deliberto, T. J., et al. (2011). Phylogenetic diversity and genotypical complexity of H9N2 influenza A viruses revealed by genomic sequence analysis. PLOS ONE 6:e17212. doi: 10.1371/ journal.pone.0017212

Gao, R., Cao, B., Hu, Y., Feng, Z., Wang, D., Hu, W., et al. (2013). Human infection with a novel avian-origin influenza A (H7N9) virus. N. Engl. J. Med. 368, 1888-1897. doi: 10.1056/NEJMoa1304459

Geiss, G. K., An, M. C., Bumgarner, R. E., Hammersmark, E., Cunningham, D., and Katze, M. G. (2001). Global impact of influenza virus on cellular pathways is mediated by both replication-dependent and -independent events. J. Virol. 75, 4321-4331. doi: 10.1128/JVI.75.9.4321-4331.2001

Geiss, G. K., Salvatore, M., Tumpey, T. M., Carter, V. S., Wang, X., Basler, C. F., et al. (2002). Cellular transcriptional profiling in influenza A virusinfected lung epithelial cells: the role of the nonstructural NS1 protein in the evasion of the host innate defense and its potential contribution to pandemic influenza. Proc. Natl. Acad. Sci. U.S.A. 99, 10736-10741. doi: 10.1073/pnas.1123 38099

Gibson-Corley, K. N., Olivier, A. K., and Meyerholz, D. K. (2013). Principles for valid histopathologic scoring in research. Vet. Pathol. 50, 1007-1015. doi: $10.1177 / 0300985813485099$

Group, S. H. W. (2013). Assessing the fitness of distinct clades of influenza A (H9N2) viruses. Emerg. Microbes Infect. 2:e75. doi: 10.1038/emi. 2013.75

Guo, Y., Li, J., and Cheng, X. (1999). [Discovery of men infected by avian influenza A (H9N2) virus]. Zhonghua shi yan he lin chuang bing du xue za zhi = Zhonghua shiyan he linchuang bingduxue zazhi. Chin. J. Exp. Clin. Virol. 13, $105-108$.

Huang, Q., Wang, K., Pan, L., Qi, K., Liu, H., and Chen, H. (2017). Co-infection of H9N2 subtype avian influenza virus and infectious bronchitis virus decreases SP-A expression level in chickens. Vet. Microbiol. 203, 110-116. doi: 10.1016/j. vetmic.2017.02.015 
Jin, H., Wang, W., Yang, X., Su, H., Fan, J., Zhu, R., et al. (2018). Evolution of H9N2 avian influenza virus in embryonated chicken eggs with or without homologous vaccine antibodies. BMC Vet. Res. 14:71. doi: 10.1186/s12917-018-1391-6

Jones, D. M., Arters, J., and Berger-Sweeney, J. (1999). Carbon dioxide-induced anesthesia has no effect on brain biogenic amine concentrations in mice. Lab. Anim. Sci. 49, 316-318.

Kash, J. C., Basler, C. F., Garcia-Sastre, A., Carter, V., Billharz, R., Swayne, D. E., et al. (2004). Global host immune response: pathogenesis and transcriptional profiling of type A influenza viruses expressing the hemagglutinin and neuraminidase genes from the 1918 pandemic virus. J. Virol. 78, 9499-9511. doi: 10.1128/JVI.78.17.9499-9511.2004

Kobasa, D., Jones, S. M., Shinya, K., Kash, J. C., Copps, J., Ebihara, H., et al. (2007). Aberrant innate immune response in lethal infection of macaques with the 1918 influenza virus. Nature 445, 319-323. doi: 10.1038/nature05495

Kohler, I., Meier, R., Busato, A., Neiger-Aeschbacher, G., and Schatzmann, U. (1999). Is carbon dioxide (CO2) a useful short acting anaesthetic for small laboratory animals? Lab. Anim. 33, 155-161.

Lin, Y. P., Shaw, M., Gregory, V., Cameron, K., Lim, W., Klimov, A., et al. (2000). Avian-to-human transmission of H9N2 subtype influenza A viruses: relationship between $\mathrm{H} 9 \mathrm{~N} 2$ and H5N1 human isolates. Proc. Natl. Acad. Sci. U.S.A. 97, 9654-9658. doi: 10.1073/pnas.160270697

Liu, D., Shi, W., and Gao, G. F. (2014). Poultry carrying H9N2 act as incubators for novel human avian influenza viruses. Lancet 383:869. doi: 10.1016/S01406736(14)60386-X

Matrosovich, M. N., Krauss, S., and Webster, R. G. (2001). H9N2 influenza A viruses from poultry in Asia have human virus-like receptor specificity. Virology 281, 156-162. doi: 10.1006/viro.2000.0799

McAuley, J. L., Tate, M. D., MacKenzie-Kludas, C. J., Pinar, A., Zeng, W., Stutz, A., et al. (2013). Activation of the NLRP3 inflammasome by IAV virulence protein PB1-F2 contributes to severe pathophysiology and disease. PLoS Pathog. 9:e1003392. doi: 10.1371/journal.ppat.1003392

Neumann, G., Macken, C. A., and Kawaoka, Y. (2014). Identification of amino acid changes that may have been critical for the genesis of A(H7N9) influenza viruses. J. Virol. 88, 4877-4896. doi: 10.1128/JVI.00107-14

Pu, J., Wang, S., Yin, Y., Zhang, G., Carter, R. A., Wang, J., et al. (2015). Evolution of the H9N2 influenza genotype that facilitated the genesis of the novel H7N9 virus. Proc. Natl. Acad. Sci. U.S.A. 112, 548-553. doi: 10.1073/pnas.142245 6112

Reed, L. J., and Muench, H. (1938). A simple method of estimating fifty percent endpoints12. Am. J. Epidemiol. 27, 493-497. doi: 10.1093/oxfordjournals.aje. a118408

Saito, T., Lim, W., Suzuki, T., Suzuki, Y., Kida, H., Nishimura, S. I., et al. (2001). Characterization of a human H9N2 influenza virus isolated in Hong Kong. Vaccine 20, 125-133. doi: 10.1016/S0264-410X(01)00279-1
Sediri, H., Schwalm, F., Gabriel, G., and Klenk, H. D. (2015). Adaptive mutation PB2 D701N promotes nuclear import of influenza vRNPs in mammalian cells. Eur. J. Cell Biol. 94, 368-374. doi: 10.1016/j.ejcb.2015.05.012

Sun, H., Yao, W., Wang, K., Qian, Y., Chen, H., and Jung, Y. S. (2017). Inhibition of neddylation pathway represses influenza virus replication and pro-inflammatory responses. Virology 514, 230-239. doi: 10.1016/j.virol.2017. 11.004

Sun, Y., and Liu, J. (2015). H9N2 influenza virus in China: a cause of concern. Protein Cell 6, 18-25. doi: 10.1007/s13238-014-0111-7

Tamura, K., Stecher, G., Peterson, D., Filipski, A., and Kumar, S. (2013). MEGA6: Molecular Evolutionary Genetics Analysis version 6.0. Mol. Biol. Evol. 30, 2725-2729. doi: 10.1093/molbev/mst197

Teng, Q., Xu, D., Shen, W., Liu, Q., Rong, G., Li, X., et al. (2016). A single mutation at position 190 in hemagglutinin enhances binding affinity for human type sialic acid receptor and replication of $\mathrm{H} 9 \mathrm{~N} 2$ avian influenza virus in mice. J. Virol. 90, 9806-9825. doi: 10.1128/JVI.01141-16

Wang, K., Huang, Q., Yang, Z., Qi, K., Liu, H., and Chen, H. (2017). Alternative reverse genetics system for influenza viruses based on a synthesized swine 45S rRNA promoter. Virus Genes 53, 661-666. doi: 10.1007/s11262-017-1457-8

Xiao, C., Ma, W., Sun, N., Huang, L., Li, Y., Zeng, Z., et al. (2016). PB2-588 $\mathrm{V}$ promotes the mammalian adaptation of H10N8, H7N9 and H9N2 avian influenza viruses. Sci. Rep. 6:19474. doi: 10.1038/srep19474

Xu, G., Zhang, X., Gao, W., Wang, C., Wang, J., Sun, H., et al. (2016). Prevailing PA mutation K356R in avian influenza H9N2 virus increases mammalian replication and pathogenicity. J. Virol. 90, 8105-8114. doi: 10.1128/JVI.00883-16

Xue, R., Tian, Y., Hou, T., Bao, D., Chen, H., Teng, Q., et al. (2018). H9N2 influenza virus isolated from minks has enhanced virulence in mice. Transbound. Emerg. Dis. 65, 904-910. doi: 10.1111/tbed.12805

Zhao, Y. X., Li, S., Zhou, Y. F., Song, W. G., Tang, Y. J., Pang, Q. H., et al. (2015). Phylogenetic analysis of hemagglutinin genes of H9N2 avian influenza viruses isolated from chickens in Shandong, China, between 1998 and 2013. Biomed Res. Int. 2015:6. doi: 10.1155/2015/267520

Conflict of Interest Statement: The authors declare that the research was conducted in the absence of any commercial or financial relationships that could be construed as a potential conflict of interest.

Copyright (C) 2019 Sun, Wang, Yao, Liu, Yang, Teng, Li, Li and Chen. This is an open-access article distributed under the terms of the Creative Commons Attribution License (CC BY). The use, distribution or reproduction in other forums is permitted, provided the original author(s) and the copyright owner(s) are credited and that the original publication in this journal is cited, in accordance with accepted academic practice. No use, distribution or reproduction is permitted which does not comply with these terms. 